\title{
Lattice Expansion and Contraction in Sputtered Metal Films due to Hydrogen Charging
}

\author{
M. E. ARMACANQUI and R. A. ORIANI \\ The Corrosion Research Center, and Department of Chemical Engineering and Materials Science, University of \\ Minnesota, Minneapolis MN 55455 (U.S.A.)
}

(Received July 11, 1986)

\section{ABSTRACT}

Hydrogen charging of Ti-30Mo plates (where the composition is in approximate weight per cent) sputtered with thin films of iron, tantalum or titanium results in an increase or decrease in the film lattice parameter, depending on the circumstances. Films thinner than $200 \mathrm{~nm}$ show continuous de. creases in lattice parameter during charging, whereas relatively thick films show positive changes in the lattice parameter. The decrease in the lattice parameter of the film metal is a consequence of fine-scale plastic deformation caused by the hydrogen charging. Mesa-like protruberances are formed in the film, which oxidize in air, causing compression of their volumes. At very small film thicknesses the contraction effect prevails because most of the film is converted into protruberances. The charging of relatively thick films causes positive changes in the lattice parameter because the expansion caused by hydrogen dissolved in the film overcomes the contraction experienced by the small volume of film near the free surface.

\section{EXPERIMENTAL DESCRIPTION}

Thin films of pure iron, tantalum and titanium were deposited by r.f. sputtering to a thickness of $200 \mathrm{~nm}$ on annealed Ti-30Mo polycrystalline plates about $0.05 \mathrm{~cm}$ thick (where the composition is in approximate weight per cent). Iron films of 1 and $5 \mu \mathrm{m}$ thickness were also deposited. In another specimen configuration, an oxide about 80 $\mathrm{nm}$ thick was deposited between the substrate and the metal film by first sputtering the pure metal in an environment of $90 \% \mathrm{Ar}$ and $10 \% \mathrm{O}$.
Samples with anodically grown oxides were also employed. Sputtering of pure titanium or tantalum was done at a power of $450 \mathrm{~W}$ in an argon environment at $10 \mathrm{mTorr}$. The target-to-substrate separation was about $5 \mathrm{~cm}$. After sputtering, and prior to hydrogen charging, the samples were heat treated in a vacuum of $3 \times 10^{-6}$ Torr for $30 \mathrm{~min}$ to produce metal films with lattice parameters equal to those of bulk metals. The sputtering of iron was done at a power of $1000 \mathrm{~W}$ and at an argon pressure equal to $15 \mathrm{~m}$ Torr, which produced a b.c.c. structure with a lattice constant of 0.2863 $\mathrm{nm}$. No heat treatment was done on the samples sputtered with iron. The sputtered plates were subjected to cathodic charging at room temperature from an electrolyte of 5 vol.\% $\mathrm{H}_{2} \mathrm{SO}_{4}$. Only the surface of the Ti-30Mo substrate was exposed to the electrolyte while the thin film side was dry and subjected to $\mathrm{X}$-ray diffraction for the measurement of the lattice parameter during charging (Fig. 1). The films were sufficiently thin to allow lattice parameter measurements of both the film and

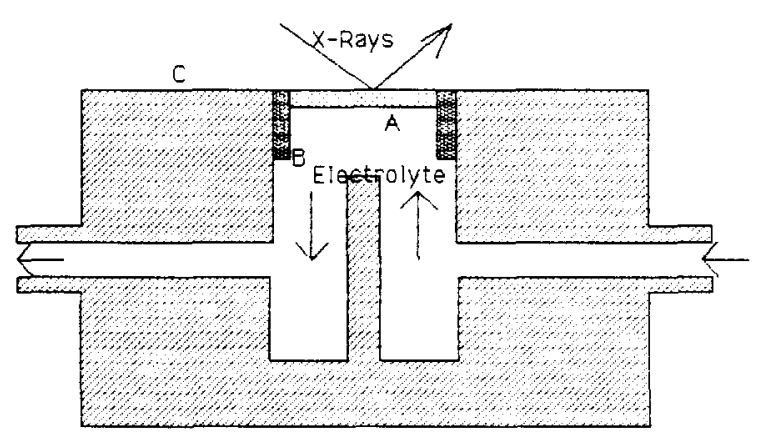

Fig. 1. Hydrogen-charging cell built to obtain contact with electrolyte over the whole area of one side of a metal plate and to allow measurement of lattice parameter changes at the other side by X-ray diffraction: A, sample; B, Tygon cell; $\mathrm{C}$, Teflon cell. 
the substrate. Charging from the film side was also done in some instances, in which case only the lattice parameter of the $\mathrm{Ti}-30 \mathrm{Mo}$ substrate was measured during charging, but that of the film was measured after charging.

\section{RESULTS}

\subsection{Hydrogen charging in thin films}

Figure 2 shows the lattice parameter changes of sputtered tantalum $200 \mathrm{~nm}$ thick and of Ti-30Mo $450 \mu \mathrm{m}$ thick charged at a current density of $3 \mathrm{~mA} \mathrm{~cm}^{-2}$. A titanium oxide layer $800 \AA$ thick was sputtered between the substrate and the tantalum film. The Ti-30Mo substrate exhibits positive changes with hydrogen charging as expected with different diffraction peaks yielding different calculated lattice parameters. This phenomenon has been observed previously and has been understood qualitatively to arise from a non-uniform concentration of dissolved hydrogen because of non-uniform trapping of hydrogen $[1,2]$. However, the tantalum film shows a decrease in lattice parameter. Poisson contraction normal to the plane of the films or bending of the specimen produced by the hydrogencaused expansion on the substrate are not the causes of the observed decrease in lattice parameter of the film [2] since the absolute values of the lattice parameter changes are about the same for both the substrate and the metal film, and hydrogen charging from the metal film side also decreased the lattice parameter of the film. Charging done on samples with titanium and iron films $200 \mathrm{~nm}$ thick gave similar results. The result of charging at

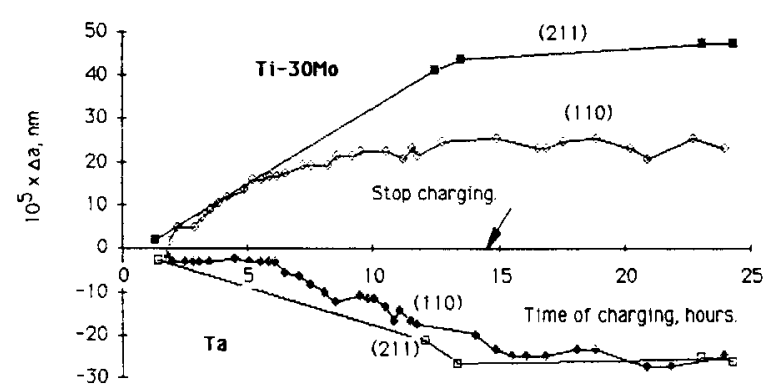

Fig. 2. Lattice parameter change $\Delta a$ at the far side in Ti-30Mo $450 \mu \mathrm{m}$ thick and in a tantalum film 200 $\mathrm{nm}$ thick during charging at $3 \mathrm{~mA} \mathrm{~cm}^{-2}$ in 5 vol. $\%$ $\mathrm{H}_{2} \mathrm{SO}_{4}$ from the substrate side.
$25 \mathrm{~mA} \mathrm{~cm} \mathrm{~cm}^{-2}$ a Ti-30Mo plate $415 \mu \mathrm{m}$ thick sputtered with $200 \mathrm{~nm}$ of iron is shown in Fig. 3. A continuous decrease in the lattice parameter of iron is observed from the beginning of the charging, and virtually no further change is observed after stopping the charging. Samples containing a layer of sputtered oxide, and charged from either side, gave about the same results as those without an intervening oxide layer. How ever, samples containing an anodically grown oxide layer between the film and the substrate showed almost no change in the substrate lattice parameter during hydrogen charging from the film side, demonstrating that the anodic oxide served as an effective barrier to hydrogen diffusion.

\subsection{Hydrogen charging in relatively thick iron films}

Iron films thicker than $200 \mathrm{~nm}$ showed positive or negative changes in lattice parameter during hydrogen charging depending on the circumstances. Figure 4 gives the results

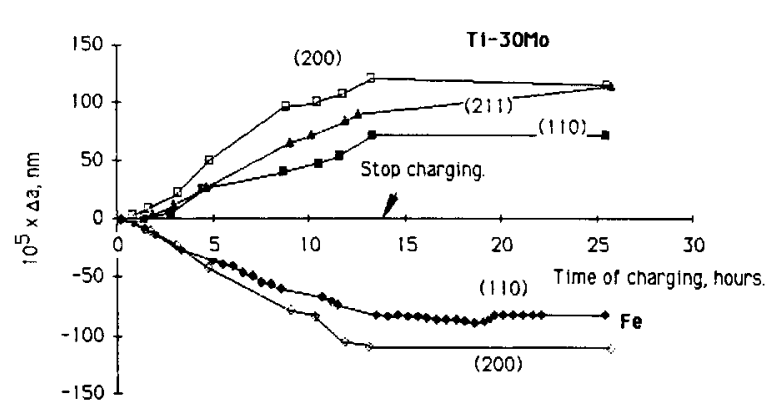

Fig. 3. Lattice parameter change $\Delta a$ in a Ti-30Mo plate and in an iron film $200 \mathrm{~nm}$ thick during cathodic charging at $25 \mathrm{~mA} \mathrm{~cm}^{-2}$ from the plate side.

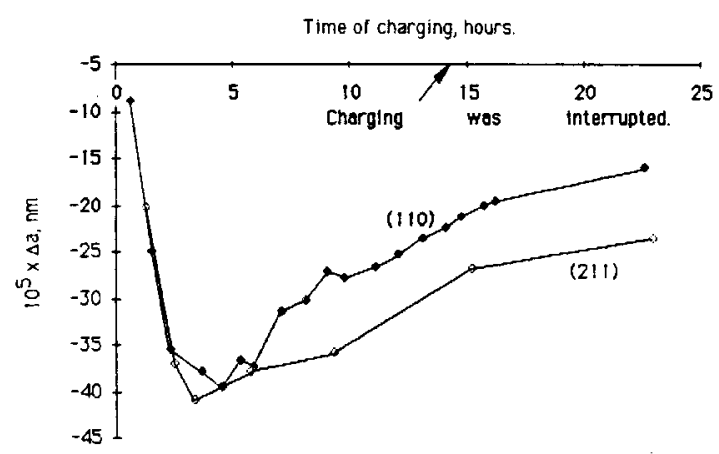

Fig. 4. Lattice parameter change $\Delta a$ in a $\mathrm{Ti}-30 \mathrm{Mo}$ plate and in an iron film $1 \mu \mathrm{m}$ thick during cathodic charging at $25 \mathrm{~mA} \mathrm{~cm}-2$ from the plate side. 
obtained with an iron film $1 \mu \mathrm{m}$ thick sputtered on $\mathrm{Ti}-30 \mathrm{Mo} 330 \mu \mathrm{m}$ thick during charging at $25 \mathrm{~mA} \mathrm{~cm}^{-2}$. A rapid decrease in the iron lattice parameter was observed during charging for the first $2.5 \mathrm{~h}$, followed by a slower increase after charging for about $6 \mathrm{~h}$. The microstructure of the film after charging showed deformation in certain areas and differed from the microstructure prior to hydrogen charging, which is shown in Fig. 5.

Charging done on samples with an iron film $5 \mu \mathrm{m}$ thick produced mostly positive changes in lattice parameter of the film. Because of the thickness of the film, only the diffraction peaks corresponding to b.c.c. iron were detected. A typical result is shown in Fig. 6. Positive changes in the film lattice parameter were observed after charging for

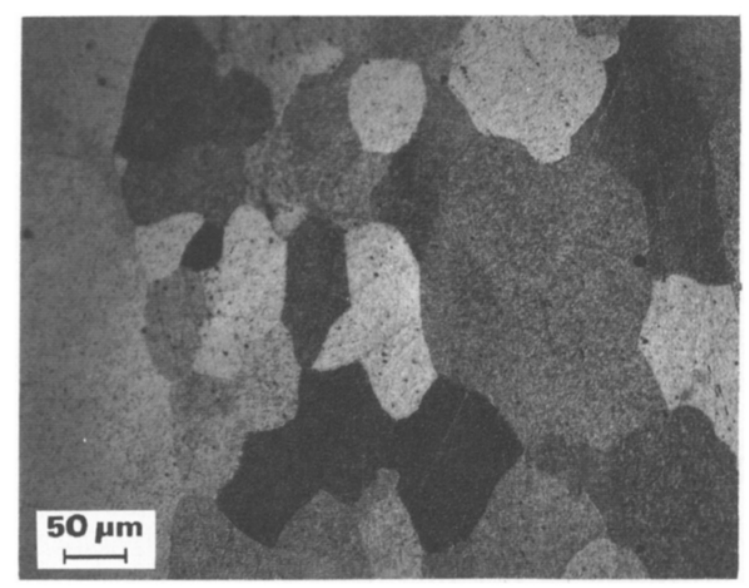

Fig. 5. Microstructure of sputtered iron $1 \mu \mathrm{m}$ thick on $\mathrm{Ti}^{-} 30 \mathrm{Mo}$ plate prior to hydrogen charging. (Magnification, $130 \times$.)

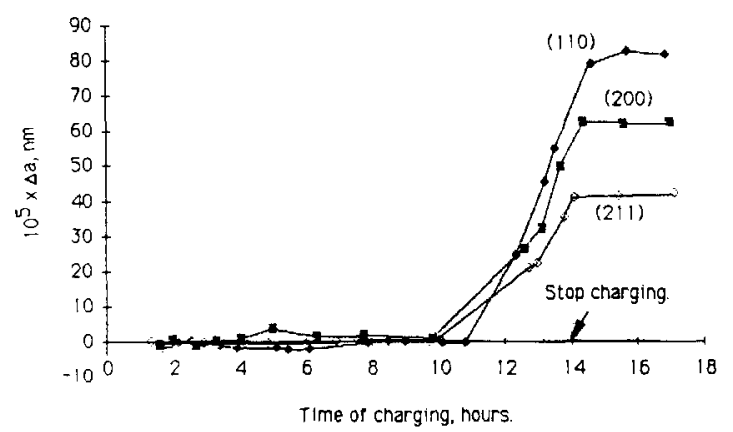

Fig. 6. Lattice parameter change $\Delta a$ in iron $5 \mu \mathrm{m}$ thick sputtered on $\mathrm{Ti}^{-30 M o}$ substrate $305 \mu \mathrm{m}$ thick subjected to charging at $20 \mathrm{~mA} \mathrm{~cm}^{-2}$ in 5 vol. $\%$ $\mathrm{H}_{2} \mathrm{SO}_{4}$.
$10 \mathrm{~h}$, which persist until the charging is interrupted $4 \mathrm{~h}$ later. A variety of values of lattice parameter develop in the iron film during hydrogen charging. This type of diversity, in which the lattice parameter depends on grain orientation, resembles the phenomenon found in bulk Ti-30Mo alloy (Figs. 2 and 3) and has the same explanation. The charging also caused extensive plastic deformation and surface rumpling of the iron film, and overall bending on the sample. Hydrogen was charged for several hours into bulk iron using the same type of electrolyte and charging cell. No change in lattice parameter was detected because of the very low solubility in the iron lattice, in accord with previous work [3]. However, extensive blistering at the entry and far sides of the sample as well as subgrains were observed, as seen in Fig. 7.

The microstructure of the film after charging appeared to show more than one phase, as seen in Fig. 8. New diffraction peaks not corresponding to b.c.c. iron or to $\mathrm{Ti}^{-} 30 \mathrm{Mo}$ alloy started to appear after charging for $12 \mathrm{~h}$. $\mathrm{X}$-ray diffraction done on the $\mathrm{Ti}-30 \mathrm{Mo}$ side showed the peaks of titanium and molybdenum hydrides, peaks that did not appear in former experiments under the same charging conditions. After these and the peaks of b.c.c. iron and b.c.c. Ti-30Mo have been accounted for, there remain additional diffraction peaks from the iron film at $2 \theta$ values equal to $27.32^{\circ}$, $28.85^{\circ}, 30.2^{\circ}, 33.0^{\circ}, 35.0^{\circ}, 37.2^{\circ}, 40.0^{\circ}$,

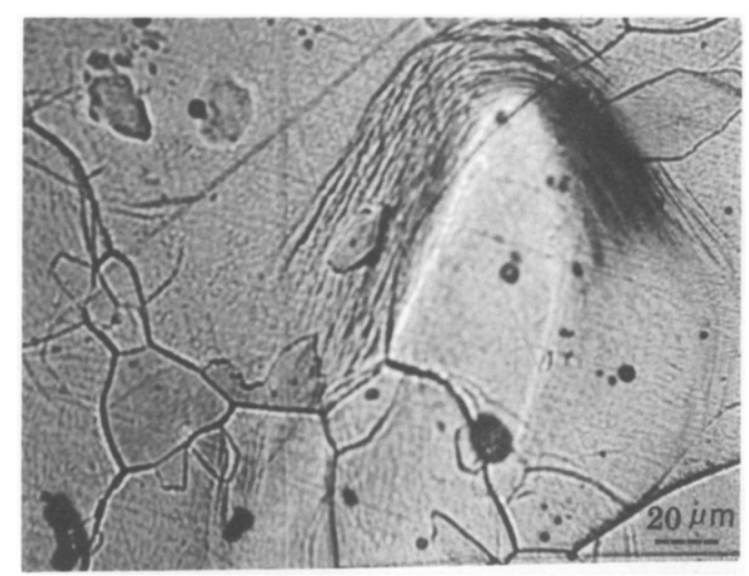

Fig. 7. Microstructure of bulk iron plate $500 \mu \mathrm{m}$ thick at its far surface after charging at $25 \mathrm{~mA} \mathrm{~cm}^{-2}$ in 5 vol. $\% \mathrm{H}_{2} \mathrm{SO}_{4}$ for $5 \mathrm{~h}$. The blistering as well as the subgrains near well-defined grain boundaries should be noted. (Magnification, 325x.) 

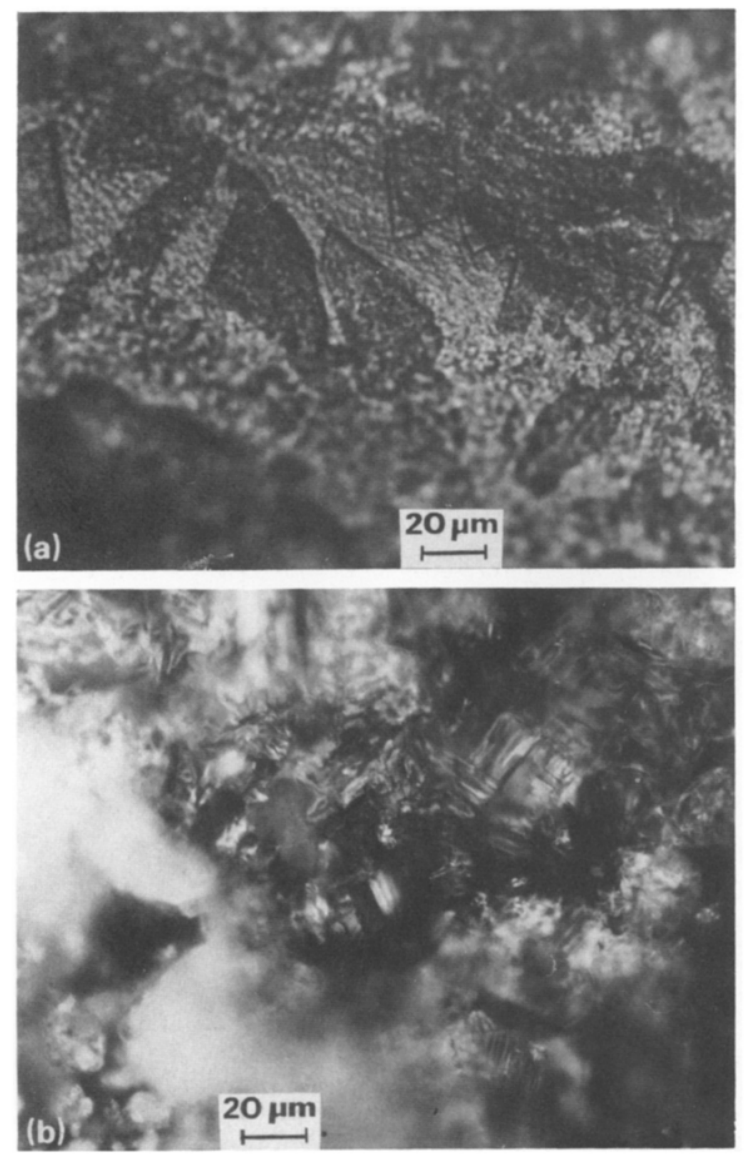

Fig. 8. (a) Microstructure of sputtered iron $5 \mu \mathrm{m}$ thick on $\mathrm{Ti}-30 \mathrm{Mo}$ plate after hydrogen charging from the substrate side at $20 \mathrm{~mA} \mathrm{~cm}{ }^{-2}$ in 5 vol, $\% \mathrm{H}_{2} \mathrm{SO}_{4}$ for $14 \mathrm{~h}$; (b) microstructure of another region of the sample shown in (a). (Magnifications, 325x.)

$43.22^{\circ}, 52.5^{\circ}, 53.7^{\circ}, 62.8^{\circ}, 73.8^{\circ}, 75.1^{\circ}$, $76.35^{\circ}, 79.2^{\circ}$ and $97.9^{\circ}$. The multiplicity of peaks makes their identification difficult. Furthermore, large amounts of sulfur were measured by energy-dispersive X-ray diffraction at the film side after hydrogen charging at the substrate side, whereas sulfur cannot be detected prior to charging. Sulfur concentrations greater than $10 \mathrm{wt} . \%$ were measured at isolated regions of the film and over a depth of about $1 \mu \mathrm{m}$. The formation of iron hydride due to hydrogen charging can be discounted because annealing which caused the sample to recover its original flatness removed the peaks of titanium and molybdenum hydrides but not the extraneous peaks in the iron film.

\section{DISCUSSION}

Increases in lattice parameter on hydrogen charging result from the expansion of the lattice unit cells by the hydrogen atoms dissolved in the metal. Decreases, however, are unexpected, and the explanation lies in the plastic deformation caused by hydrogen charging [4]. The hydrogen-caused plastic deformation of the Ti-30Mo substrate causes portions of the overlying metal film to be moved relative to their original positions. Because various slip systems are operating within one grain, the result of slip is the formation of mesa-like protruberances, and the overall surface-tovolume ratio of the film metal becomes much larger than that prior to hydrogen charging. Fresh surfaces of the film are thus exposed to air and oxidize. We hypothesize that the stresses accompanying the air oxidation of the protruberances put their interior atoms into compression, and this causes the lattice parameter of the film to decrease. Mesa-like formations were observed on iron films $5 \mu \mathrm{m}$ thick after charging at $25 \mathrm{~mA} \mathrm{~cm}^{-2}$ (Fig. 9). A protruberance size of about $60 \mathrm{~nm}$ in diameter would account for the decrease in lattice parameter due to air oxidation of fresh surfaces in the metal film [4]. We suggest that two effects are operating during hydrogen charging. One of these is the expansion caused by hydrogen dissolved in the film metal, and it is opposed by the second effect, the contraction induced by the compressive stresses resulting from the oxidation of the protruberances. At very small thicknesses the contraction effect prevails. The determining factor is the surface-to-volume ratio in the film after hydrogen charging.

By interferometric measurements the average height of the slip steps caused by hydrogen charging at $25 \mathrm{~mA} \mathrm{~cm}{ }^{-2}$ for $3 \mathrm{~h}$ was found to be approximately $220 \pm 20 \mathrm{~nm}$. A metal film $200 \mathrm{~nm}$ thick is therefore expected to be mostly converted into protruberances. In this case the film experiences mostly compressive stresses; this causes negative changes in lattice parameter and also a decrease in hydrogen solubility [5]. If the metal film has a thickness of $5 \mu \mathrm{m}$, the normal expansion caused by hydrogen in the film lattice overcomes the contraction produced by the compressive stresses in the protruberances since 

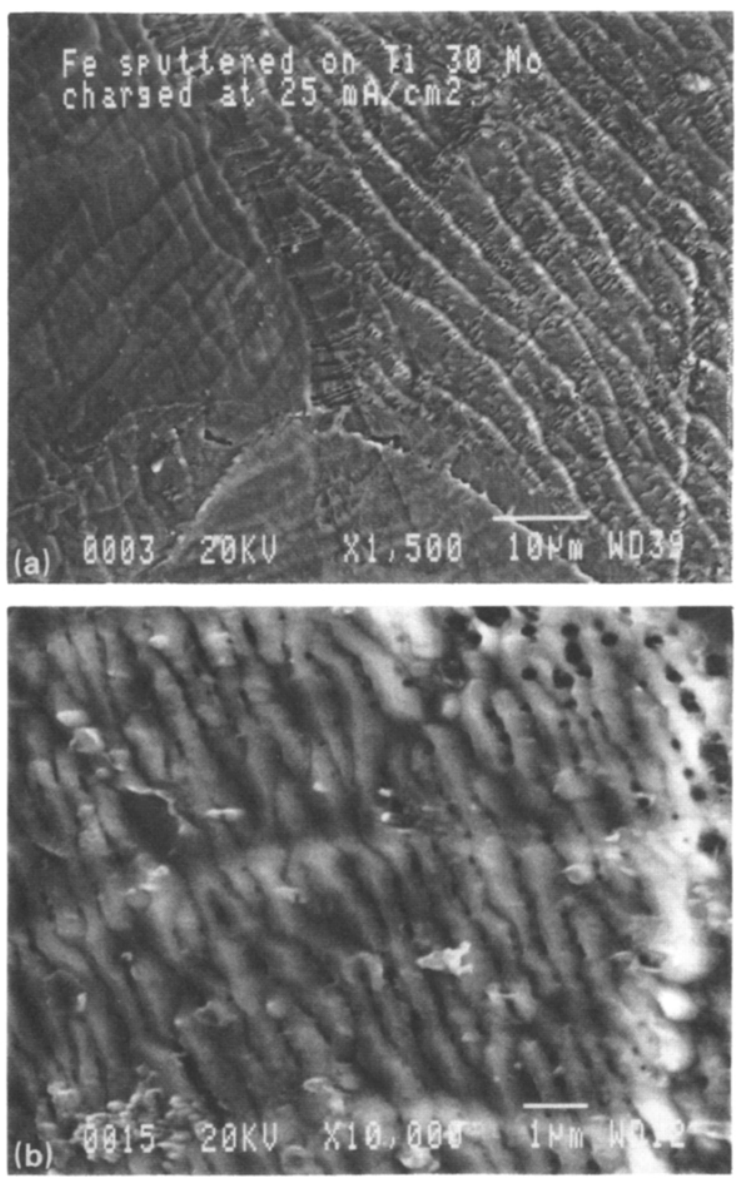

Fig. 9. (a) Microstructure of sputtered iron $5 \mu \mathrm{m}$ thick on $\mathrm{Ti}^{-} 30 \mathrm{Mo}$ plate after hydrogen charging from the substrate side at $25 \mathrm{~mA} \mathrm{~cm}{ }^{-2}$ in 5 vol. $\% \mathrm{H}_{2} \mathrm{SO}_{4}$ for $14 \mathrm{~h}$, showing mesa-like formations; (b) microstructure of another region of the sample shown in (a). (Magnifications: (a) $975 \times$; (b) 6500x.)

only a small volume of the film experiences compression. Therefore, positive changes in the film lattice parameter are observed. In our view, the decrease in lattice parameter of the film metal observed by hydrogen charging is a consequence of fine-scale plastic deformation and air oxidation. Hydrogen is not intrinsically involved but serves only as a means for plastic deformation. Therefore, any other way of producing sufficiently fine-scale slip should also cause a lattice parameter contraction near the surface. However, unless a film of a dissimilar metal is deposited on a substrate, the effect will be difficult to observe because the diffracted beam would respond mostly to the metal deeper than the upper $200 \mathrm{~nm}$ or so.
The maximum positive change in lattice parameter measured in the iron film was about $9 \times 10^{-4} \mathrm{~nm}$. This value represents a latticedissolved hydrogen concentration of approximately $570 \mathrm{ppm}$, using the known partial volume of hydrogen in $\alpha$-Fe of $2 \mathrm{~cm}^{3} \mathrm{~mol}^{-1}$ [6]. From the known solubility of hydrogen in iron at $1 \mathrm{~atm}$ [7], and the use of Sieverts' law, the fugacity of hydrogen corresponding to a solubility of $570 \mathrm{ppm}$ is found to be approximately $10^{12} \mathrm{~atm}$. This very large value compels us to postulate that the large population of hydrogen trapped at dislocations in the iron film is also contributing to the enlarged lattice parameter since hydrogen at dislocation cores has a non-zero partial molal volume [8]. Nevertheless, a very large lattice concentration and therefore a very large fugacity value must be present. Hydrogen charged into bulk iron at similarly high fugacities causes extensive blistering by the precipitation of molecular hydrogen within microvoids with a negligible amount of hydrogen retained in solid solution. This contrasts strongly with the behavior here observed in iron films sputtered on $\mathrm{Ti}-30 \mathrm{Mo}$ substrates.

The new phases formed after charging for some hours on samples containing $5 \mu \mathrm{m}$ of iron film may be related to the amounts of sulfur found in this film. Energy-dispersive $\mathrm{X}$-ray analysis of the iron film at points corresponding to the new phases shown in Fig. 8 gave unexpectedly large amounts of sulfur. Also, sulfur, up to about $17 \mathrm{wt} \%$, was found on the surface at the entry side of the Ti-30Mo substrates. Therefore the sulfur probably originated from the sulfuric acid electrolyte. For sulfur to appear at the film side of the sample, it must diffuse through the $\mathrm{Ti}-30 \mathrm{Mo}$ substrate. The phase found at the film side of the composite is probably iron sulfide and is not removed by annealing at $550{ }^{\circ} \mathrm{C}$ for 30 min. Sulfur absorption and diffusion in metal films exposed to sulfur dioxide at $85^{\circ} \mathrm{C}$ have been reported [9].

\section{CONCLUSIONS}

(1) Hydrogen charging in $\mathrm{Ti}^{-} 30 \mathrm{Mo}$ plates sputtered with metal films thinner than 200 $\mathrm{nm}$ causes a decrease in the lattice parameter of the thin film. The decrease is a result of 
compressive stresses developed in the film volume because of air oxidation of fresh surfaces created by plastic deformation.

(2) Hydrogen charging in Ti-30Mo substrates sputtered with iron films $5 \mu \mathrm{m}$ thick causes a net increase in the film lattice parameter. The expansion in most of the film metal lattice by the dissolved hydrogen overcomes the near-surface effect.

(3) Iron films of $5 \mu \mathrm{m}$ thickness absorb hydrogen into solid solution under input fugacities that produce extensive blistering in bulk iron.

(4) Hydrogen charging in the (Ti-30Mo)film composite from a dilute solution of sulfuric acid results in the absorption and diffusion of sulfur into the metal, and the formation of a sulfur-containing phase in the overlying iron film.

\section{ACKNOWLEDGMENT}

This research was supported by the U.S. Department of Energy, Office of Basic Energy
Sciences, under Contract DOE/DE-FG0284ER 45173.

\section{REFERENCES}

1 M. E. Armacanqui and R. A. Oriani, Corrosion, 41 (1985) 287.

2 M. E. Armacanqui and R. A. Oriani, Mater. Sci. Eng., 91 (1987) 143.

3 A. S. Tetelman, C. N. J. Wagner and W. D. Robertson, Acta Metall., 9 (1965) 205.

4 M. E. Armacanqui and R. A. Oriani, Scr. Metall., $19(1985) 525$.

5 J. C. M. Li, R. A. Oriani and L. S. Darken, Z. Phys. Chem. N.F., 49 (1966) 271.

6 R. A. Oriani, Trans. Metall. Soc. AIME, 236 (1966) 1368 .

7 O. D. Gonzales, cited by R. A. Oriani, in R. W. Staehle, A. J. Forty and D. Van Rooyen (eds.), Proc. Conf. on Fundamental Aspects of Stress Corrosion Cracking, National Association of Corrosion Engineers, Houston, TX, 1968, pp. 32-50.

8 R. Kirchheim, Acta Metall., 34 (1986) 37.

9 R. R. Dubin and K. D. Winn, IEEE Trans. Magn., 19 (1983) 1665 